\title{
HPTLC simultaneous quantification of triterpene acids for quality control of Plantago major L. and evaluation of their cytotoxic and antioxidant activities
}

\author{
Kartini $^{\mathrm{a}, \mathrm{b}, *}$, S. Piyaviriyakul ${ }^{\mathrm{c}}$, P. Siripong ${ }^{\mathrm{c}}, \mathrm{O}$ Vallisuta $^{\mathrm{a}}$ \\ a Faculty of Pharmacy, Mahidol University, 447 Sri-Ayudhaya Road, Ratchathewi, Bangkok 10400, Thailand \\ ${ }^{\mathrm{b}}$ Faculty of Pharmacy, University of Surabaya, Raya Kalirungkut Road, Surabaya 60293, Indonesia

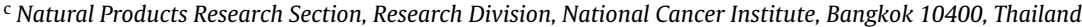

\section{A R T I C L E I N F O}

\section{Article history:}

Received 12 March 2014

Received in revised form 11 June 2014

Accepted 13 June 2014

\section{Keywords:}

Cytotoxic

Antioxidant

Ursolic acid

Oleanolic acid

HPTLC

Simultaneous analysis

\begin{abstract}
A B S T R A C T
A validated high performance thin-layer chromatography (HPTLC) method was developed for simultaneous determination of ursolic acid (UA) and oleanolic acid (OA) contents in Plantago major which were collected from several plantation areas in Indonesia. The cytotoxic effect against two cancer cell lines, SiHa and Hep G2, and antioxidant activity were evaluated using the MTT and DPPH-radical scavenging assay, respectively. The test samples included various extracts of $P$. major from different plant parts using methanol and water as extracting solvents and pure compounds derived from this plant. The results showed that both plant parts and extracting solvents affected the chemical contents and their biological activities. The contents of UA and OA varied according to the organs and provenances of plant. The highest content of UA (0.22-0.48\% dry weight) and OA $(0.17-0.33 \%$ dry weight) were found in the methanol extract of seed. This extract also exhibited the highest cytotoxic activity $\left(\mathrm{IC}_{50}\right.$ value: $174.42-246.38 \mu \mathrm{g} / \mathrm{ml}$ ), whereas the strongest free radical scavenging activity was obtained from the leaf methanol extract (IC 50 value: $263.57 \mu \mathrm{g} / \mathrm{ml}$ ). The developed HPTLC method can be used for routine analysis and standardization of $P$. major crude drugs, extracts, and/or finished products using UA and OA as appropriate markers for anticancer products.
\end{abstract}

(C) 2014 Elsevier B.V. All rights reserved.

\section{Introduction}

Plantago major L. is a member of Plantago genus (Plantaginaceae family) having more than 256 species (Galvez et al., 2005). This perennial plant is globally distributed and found in remarkably different locations and climatic conditions, from sea level up to $3300 \mathrm{~m}$ altitude. It is generally accepted that environment affects chemicals composition, which then affect the biological activities of medicinal plants (Zhang et al., 2009). The decoction of aerial parts of $P$. major, its leaves or seeds, are used traditionally as diuretic, laxative, anti-diabetes, and for skin diseases. The root is empirically used as anti-cough (de Padua and Bunyapraphatsara, 1999). At present, several herbal medicine industries in Indonesia commercialize this plant into modern dosage forms such as capsules and tablets without any standardization of the products. Only the aerial parts are

\footnotetext{
* Corresponding author at: Faculty of Pharmacy, Mahidol University, 447 SriAyudhaya Road, Ratchathewi, Bangkok 10400, Thailand. Tel.: +66 026448677.

E-mail addresses: kartini240777@gmail.com, kartini@ubaya.ac.id ( Kartini).
}

being used, whereas the roots become waste without any usage. Further studies are required to maximize its utilization.

Plantago major contains various classes of compound such as flavonoids (e.g., baicalein), iridoid glycosides (e.g., aucubin and catalpol), triterpene acids (e.g., ursolic acid and oleanolic acid), caffeic acid derivatives (e.g., caffeic acid and chlorogenic acid), and phenolic compounds (e.g., vanillic acid and p-coumaric acid) (Samuelsen, 2000). Ursolic acid (UA) and oleanolic acid (OA) (Fig. 1.) are highly interesting due to their broad spectrum of activities; i.e. COX-2 and cholinesterase inhibitor (Kolak et al., 2011; Ringbom et al., 1998; Stenholm et al., 2013), immunomodulator (Chiang et al., 2003c), and cancer prevention and treatment (Chiang et al., 2003a; Kolak et al., 2011; Lee et al., 2005; Liu, 1995, 2005; Pollier and Goossens, 2012; Ringbom et al., 1998; Shanmugam et al., 2013; Stenholm et al., 2013). Various determination methods such as GC-MS (Caligiani et al., 2013; Janicsák et al., 2003), HPLC (Wang et al., 2011a; Wang et al., 2008; Wójciak-Kosior et al., 2013), LC(UV)-APCI-MS (Tarvainen et al., 2010), and 2D NMR (Kontogianni et al., 2009) were applied to quantify the UA and OA content in some plants, including $P$. major. These methods, however, are high cost, time-consuming, and specialized expertises are needed. For these 